\title{
Seagrass Distribution in China with Satellite Remote Sensing
}

\author{
Yang Dingtian and Yang Chaoyu \\ State Key Laboratory of Tropical Oceanography, \\ South China Sea Institute of Oceanology, \\ Chinese Academy of Sciences, Guangzhou
}

China

\section{Introduction}

In nowadays, seagrass has been regarded as one of the healthy indexes for costal ecosystem, for it can provide shelter for fish living and laying egg, and also provide food for fish, tortoise, Dugong and seabirds. Management and preservation of coastal marine resources is a formidable challenge given the rapid pace of change affecting coastal environments. Fast, accurate, and quantitative tools are needed for detecting change in coastal ecosystems. Traditional in-situ surveys are time and labor intensive, generally lack the spatial resolution and precision required to detect subtle changes before they become catastrophic, and can be difficult to maintain from year to year (Orth \& Moore, 1983, Peterson \& Fourqurean 2001). In recent times satellite technology has played a vital role in seagrass monitoring. Remote sensing was a useful method for detection of land use change and seagrass. Satellite remote detecting of seagrass was different from that of terrestrial vegetation for water absorbing greatly at red and infer-red spectrum. When seagrass distributed underwater, visible spectrum was often used to detect the density and living state of seagrass. Lennon introduced the advantage of satellite remote sensing on detection of seagrass in 1989 and regarded red, blue and green as the most useful channel for detecting seagrass distribution (Lennon, 1989). Dahdouh-Guebas (1999) also used channel of blue, red and green to map the distribution of seagrass in Kenyan coast. Understanding of light scattering by plant canopies is crucial for remote sensing quantification of vegetation abundance and distribution (Jacquemoud et al. 1996). Hyperspectral data is very useful for assessing seagrass resources as it contains plentiful information. High turbidity is one of the important reasons for seagrass decline and usually was a problem for detection of seagrass with remote sensing. Phinn (2005) retrieved the seagrass along the coast of Moreton Bay, Australia and found that seagrass in turbid water was relatively difficult to detect. After studied variation of seagrass distribution and species affected by land use change, Batish (2002) concluded that hurricane and strong rainfall was the main factors for mud losing and sediment resuspension, which increased the water turbidity. The need for precise detection of living status and distribution of seagrass led some researchers to use high resolution remote sensing data. Among them SPOT data was very useful, for it had spatial resolution of $2.5 \mathrm{~m}, 5 \mathrm{~m}, 10 \mathrm{~m}$ and four bands

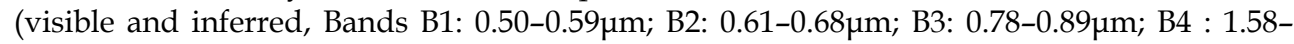
$1.75 \mu \mathrm{m}$ with a resolution of $20 \mathrm{~m}$ ). Pasqualini (2005) used SPOT 5 data to map the 
distribution of Posidonia oceanica along Zakinthos Island in Greece with Principal Component Analysis, obtained good results and the accuracy was between $73 \%-96 \%$. However, SPOT data only have two visible bands, which limited the use of image for retrieval of substrate information. IKONOS was another satellite data with high resolutions. Some researchers used the IKONOS data to retrieve the types of sea bottom and seagrass distribution. Andrefouet (2005) used IKONOS data to classify tropical coral reef environment, overall accuracy was $77 \%$ for $4-5$ classes, $71 \%$ for $7-8$ classes, $65 \%$ in $9-11$ classes, and 53\% for more than 13 classes. Compared with SPOT data, IKONOS and Quickbird have their advantage on more bands cover visible spectrum. Compared with IKONOS data, Quickbird is better for higher spatial resolution. Some researchers compared Quickbird data with Landsat-5 and CASI data, the conclusion was reached that Quickbird was better for mapping of seagrass cover, species and biomass to high accuracy levels (> 80\%) (Phinn et al. 2008).

New technology provided by ocean color remote sensing provides high spatial and temporal resolution of the benthos, but the application of ocean color data in shallow waters is still in its early stage. Unverified classification techniques neglect the confounding effects of reflectance from benthos and spectral shifts, and this can lead to considerable errors. In optically shallow water, the radiance can be modified due to spectral scattering and absorption by phytoplankton, suspended organic and inorganic matter and dissolved organic substances (Dekker et al., 1992). Therefore, more efforts should be paid in accuracy of classification of seagrass on water column correction. A foremost problem for mapping seagrass by analysis of remote sensing data is water column effect. Most photons are absorbed or scattered by all particulates in optically shallow water (Morel et al.1977, Gordon et al., 1983). So water depth and water column inherent optical properties must be measured for mapping seagrass (Holden et al., 2001). While most water column correction procedures may not be appropriate for mapping or deriving quantitative information of seagrass. For instance, simply subtracting a deep-water remote sensing reflectance from each pixel is based on the assumption that energy traveling through a water column behaves the same way regardless of substrate type and water depth. In fact, when light penetrates water its intensity decreases exponentially with increasing depth. This process is known as attenuation and it exerts a profound effect on remotely sensed data of aquatic environment. The severity of attenuation differs with the wavelength of electromagnetic radiation. The single/quasi-single scattering theory and numerical simulations are often used to estimate water column effects (Liang, 2007). In these approaches a parameterized forward model for reflectance such as Hydrolight (for aquatic applications) takes a series of parameters describing the optical properties of participating media or canopy structure. Image analysis then uses a search algorithm to find the parameter space location which minimizes the distance of the corresponding spectral space location from the image pixel reflectance (Goodman \& Ustin, 2007). With the approach, the model may take substantial computational effort. Often the model is simplified or approximated to facilitate inversion. So, model accuracy must be compromised. Conger et al. (2006) applied the approach separating determinations of the spectral albedos of typical materials covering the floor (Morel, 1993) to develop a simple technique to merge SHOALS (Scanning Hydrographic Operational Airborne Lidar Survey) LIDAR bathymetry data with Quickbird data. The remote sensing data with respect to depth was linearized in the model by subtracting an optically deep water value from the entire waveband under consideration and taking the 
natural logarithm of the result. Subtracting a deep-water remote sensing reflectance from each pixel (Cannizzaro \& Carder, 2006) or utilizing the water optical properties which are derived from adjacent deep waters, were used to correct water column effects. Modeled shallow water reflectance typically has an inverse exponential relationship with depth (Mobley, 1994), so a regular subdivision of a depth parameter would over-sample the deep water spectral space region with similar reflectance spectra produced from unnecessary forward model runs. At the same time the shallow water spectral space region would be relatively under-sampled with a higher discretization error in the tabulated reflectance (Froidefond \& Ouillon, 2005). The interaction between multiple parameters (e.g. depth vs. water clarity) makes the general problem of efficient and accurate LUT (look-up tables) construction very hard to tackle by analytical means (Hedley et al., 2009). Routine or largescale operational image analysis by physics-based methods therefore demands the development of efficient approaches for both modeling and inversion. Often the model is simplified or includes too many parameters which cannot be measured directly (i.e. the attenuation coefficients for the upward streams originating from the water column and from the bottom) (Sathe \& Sathyendranath, 1992; Nichols \& Kyrala, 1992). In our investigation an optical model of in-coming solar radiation transfer was developed, in which multi-layer water was considered. Implementation of the method was found to be effective for improving the accuracy of coastal habitat maps and essential for deriving empirical relationships between remotely sensed data and interested features in the marine environment. Retrieved bottom reflectance was then used to study the relationship between reflectance and the LAI (leaf area index) of seagrass. In addition, it was found that the peak location of retrieved bottom reflectance was highly correlated to LAI of seagrass measured in Sanya Bay, South China Sea. Then, this paper studied the seagrass distribution along the northeast coast of Xincun Bay and Sanya Bay. The first aim was to give a regional bio-optical model of seagrass for detecting seagrass distribution with high accuracy. The second was to provide the information of seagrass distribution and living state for government and people to understand how to preserve and protect seagrass.

\section{Water column model}

In our investigation an optical model of in-coming solar radiation transfer was adopted, in which multi-layer water was considered (Yang et al. 2010). This algorithm which had been

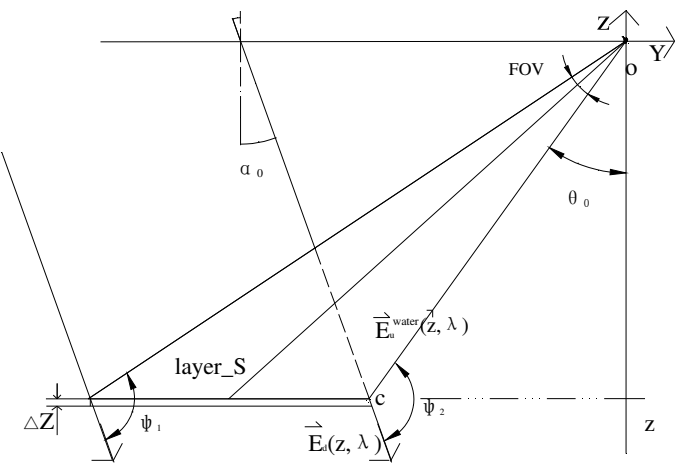

Fig. 1. The optical model of light propagation in optically shallow water 
used to successfully extract seagrass and coral reefs information in Sanya Bay enables us to simulate radiation fields in a wide range of optical characteristics of these layers to analyse the mechanisms of the formation of the radiation characteristics inside and outside the layers, and to estimate any contribution of each region. Differences in water column properties would only modify the input to the equation for retrieving bottom reflectance but not the equation.

At the core of the inversion method by Yang et al. (2010) lies an analytical expression for $R_{r s}^{\text {water }}\left(0^{-}, \lambda\right)$, subsurface remote sensing reflectance of the water column, for an optical shallow water body:

$$
\begin{aligned}
& R_{r s}^{\text {water }}\left(0^{-}, \lambda\right)=Q \cdot\left(\frac{\exp \left(-2 k(\lambda)\left(z-z_{\text {surf }}\right)\right)-1}{-2 k}\right) \cdot \\
& {\left[-2 \pi \beta_{w}\left(90^{\circ}, \lambda_{0}\right) \cdot\left(\frac{\lambda_{0}}{\lambda}\right)^{4.32} \cdot\left(\cos \Psi+\frac{0.835}{3} \cos ^{3} \Psi\right)-\frac{b_{p}}{2 g} \cdot \frac{1-g^{2}}{\left(1+g^{2}-2 g \cos \Psi\right)^{1 / 2}}\right]_{\psi_{1}}^{\psi_{2}}}
\end{aligned}
$$

Where $Q$ is the radio of the subsurface upward irradiance to radiance conversion factor, and has a value of 3.25 (Morel \& Gentili 1993) ; $\lambda$ is the wavelength; $k$ is a unique attenuation coefficient which is invariable with respect to depth; $z$ is water depth measured downward from the detector; $z_{\text {surf }}$ is the distance between ocean surface and the detector; $\beta_{w}(\psi, \lambda)$ is the total volume scattering function (VSF) for pure seawater (Morel 1977); Morel gave the values of $\beta\left(90^{\circ}, \lambda_{0}\right)$ at the reference wavelengths of 350 and $600 \mathrm{~nm}$, and $\lambda_{0}$ is the wavelength value selected from the reference wavelength table; The wavelength dependence of $\lambda-4.32$ results from the wavelength dependence of the index of refraction; The factor 0.835 is attributed to the anisotropic properties of the water molecules (Chami et al. 2006); $b_{p}$ is the particle scattering coefficient; $g$ is a parameter that can be adjusted to control the relative

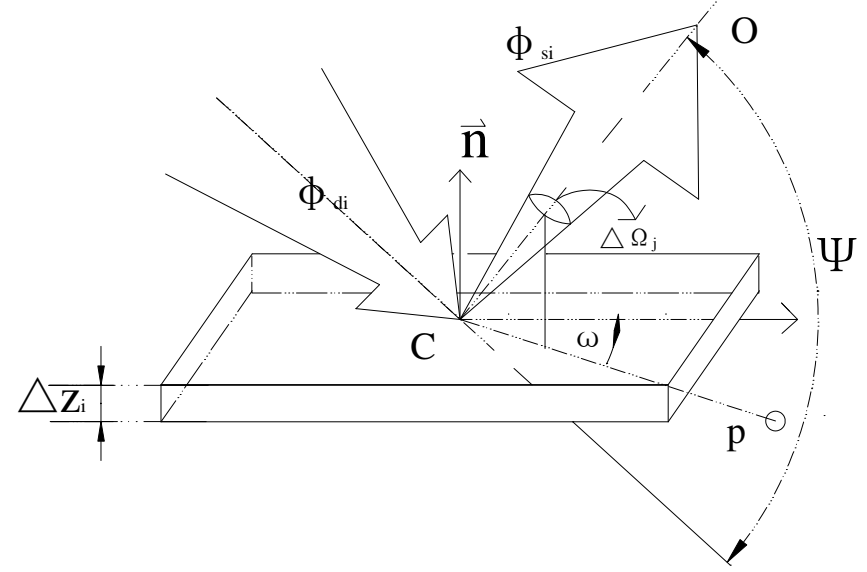

Fig. 2. The fraction of incident power scattered out of the beam through an angle $\psi$ into a solid angle $\Delta \Omega_{j}$. 
amounts of forward and backward scattering in $\beta_{H G}$, Henyey-Greenstein phase function (Henyey-Greenstein, 1941); $\mathrm{R}(0-, \lambda)$ is the irradiance reflectance just beneath the sea surface.

In addition, $\psi$ is the angle of reflection of the incident beam; $\psi_{1}$, and $\psi_{2}$ can be expressed as:

$$
\begin{aligned}
& \Psi_{1}=-\left(\alpha_{0}+\theta_{0}+\frac{F O V}{2}\right)+\pi \\
& \Psi_{2}=-\left(\alpha_{0}+\theta_{0}-\frac{F O V}{2}\right)+\pi
\end{aligned}
$$

Where, FOV is the field of view of the sensor, $a_{0}$ is the solar attitude, and $\theta_{0}$ is the view angle. In addition, the final signal detected by the receiver results from the flux reflected by the bottom (as if the bottom were black) and the flux reflected by the bottom (when it is not black) (Maritorena et al., 1994). For simplification, reflectance, mentioned below, represents the remote sensing reflectance. Finally, we can get the bottom reflectance, $R_{r s}{ }_{r}$ :

$$
R_{r s}^{b}=R_{r s}\left(0^{-}, \lambda\right)-R_{r s}^{\text {water }}\left(0^{-}, \lambda\right)
$$

Here $R$ is the total irradiance radio just below the surface.

\section{Results and analysis}

\subsection{The difference between uncorrected and corrected reflectance}

Fig. 3 shows the retrieved bottom reflectance was lower than the in situ measured reflectance and the change between the corrected and uncorrected reflectance did exist (Fig. 4) (Yang et al. 2010). The range of the variation varied widely, and the difference was much larger at $400-450 \mathrm{~nm}$. The variation in spectral reflectance was determined mainly by absorption and scattering properties of shallow water.

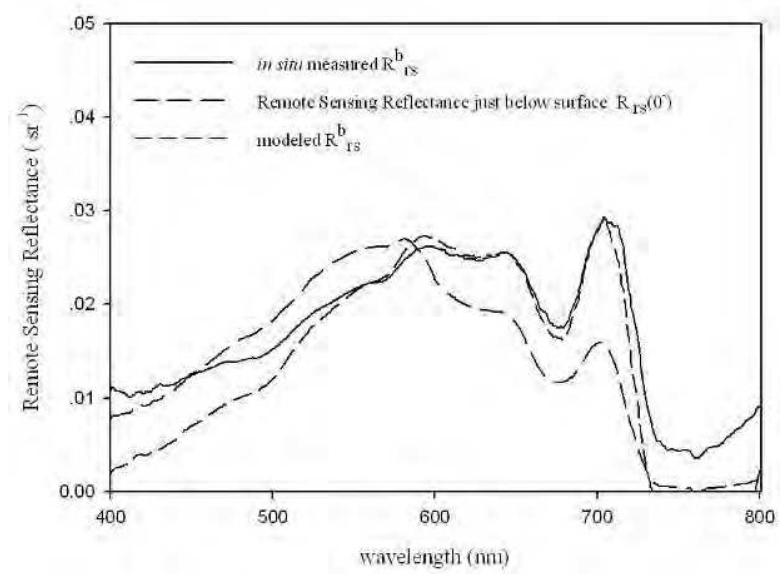

Fig. 3. Reflectance spectra of seagrass; $\mathrm{R}_{\mathrm{rs}}\left(0^{-}\right)$represents subsurface remote-sensing reflectance; $R_{\mathrm{rs}}{ }^{\mathrm{b}}$ represents the bottom reflectance (Yang et al. 2010). 

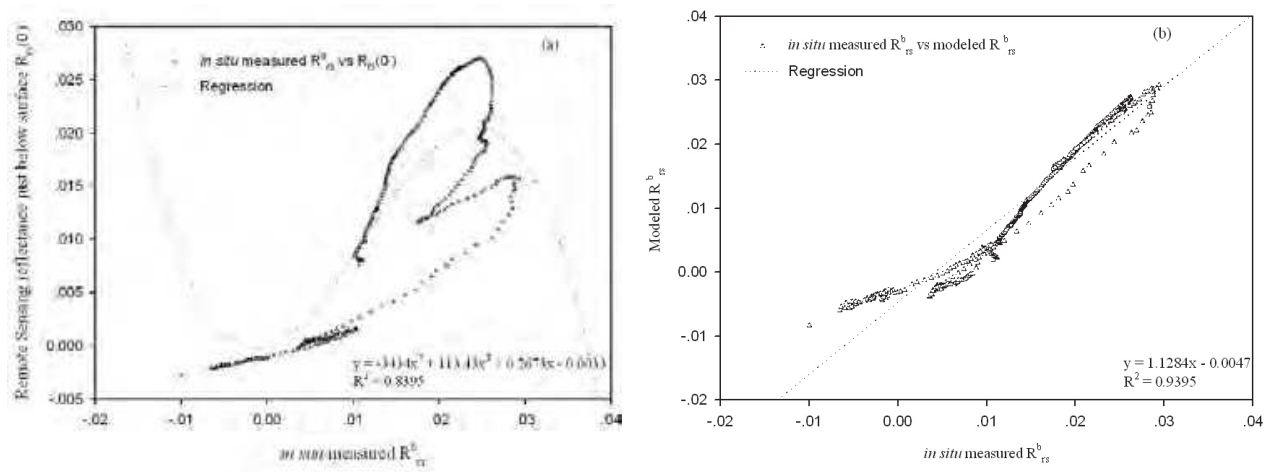

Fig. 4. (a) Comparison of the in situ measured bottom reflectance with subsurface remotesensing reflectance; (b) Comparison of the in situ measured bottom reflectance with the retrieved bottom reflectance from the optical model; $\mathrm{R}_{\mathrm{rs}}\left(0^{-}\right)$represents subsurface remotesensing reflectance; $R_{r s}{ }^{b}$ represents the bottom reflectance (Yang et al. 2010).

\subsection{Spectral characteristics of seagrass}

Fig. 5 shows that the reflectance of Thalassia increased between 518 and $532 \mathrm{~nm}$, which might indicate changes in xanthophyl-cycle pigmentation. In South China Sea the leaves of Thalassia display olive-drab color, and this just coincides with the relevant spectral features of Thalassia detected around $550 \mathrm{~nm}$. The reflectance differences between 600 and $650 \mathrm{~nm}$ can mainly be attributed to different proportions of red, orange, yellow and brown carotenoids. Between 650 and $680 \mathrm{~nm}$ reflectance decreased, and that suggests reduced absorption of light by chlorophyll, which may be resulted from reduction in chlorophyll. The reflectance overlapped around 720nm may be relative to the total effect whereby the relationship between light harvesting efficiency and chlorophyll content is non-linear due to pigment self-shading among thyllakoid layers. The particularly strong package e ffect observed in seagrass was largely attributed to restriction of chloroplasts to the leaf epidermis (Cummings et al. 2003, Enriquez 2005). Zone between 800 and $840 \mathrm{~nm}$

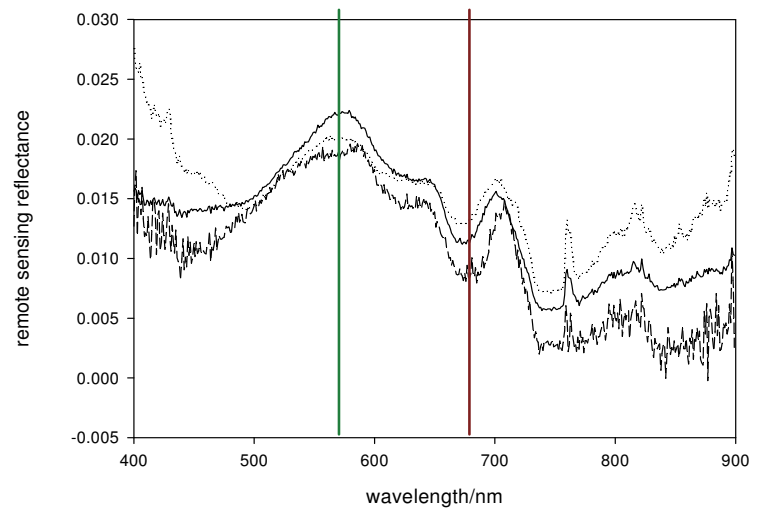

Fig. 5. The remote sensing reflectance of seagrass meadows (Yang et al. 2010). 
encompasses a spectral region of maximum reflectance, although a weak water absorption feature occurs near the $812 \mathrm{~nm}$ (Becker et al. 2005). In addition, the seagrass can also spectrally be identified with leaf samples coated by epibionts including a diverse array of microalgae, bacteria, juvenile macroalgae and sessile invertebrates such as tubeworms and bryozoans. It was found that seagrass reflectance reduced drastically at the green peak without having a noticeable effect on the chlorophyll absorbance trough in infrared. However, biliproteins of algal epibionts were responsible for the increased reflectance peaks observed between $560-670 \mathrm{~nm}$.

\subsection{LAl and the spectral response}

The spectral reflectance of seagrass measured at different station changed regularly with LAI. The bands with good relationship with LAI were 555,635, 650 and $675 \mathrm{~nm}$ (Yang and Yang 2009), for absorption and reflectance of seagrass photosynthetic and accessory pigment (Fig. 6), and correlation coefficient of quadratic equation was greater than 0.79 . These results can be explained as lower leaf area index the exposed area of sediment was greater, and water leaving radiance from seagrass bed is weaker; with higher seagrass LAI, water leaving radiance from bottom is dominant by seagrass and increased with increasing LAI. Previous study showed that the bands with good relationship with LAI were 555,635, 650 and $675 \mathrm{~nm}$, for absorption and reflectance of seagrass photosynthetic and accessory
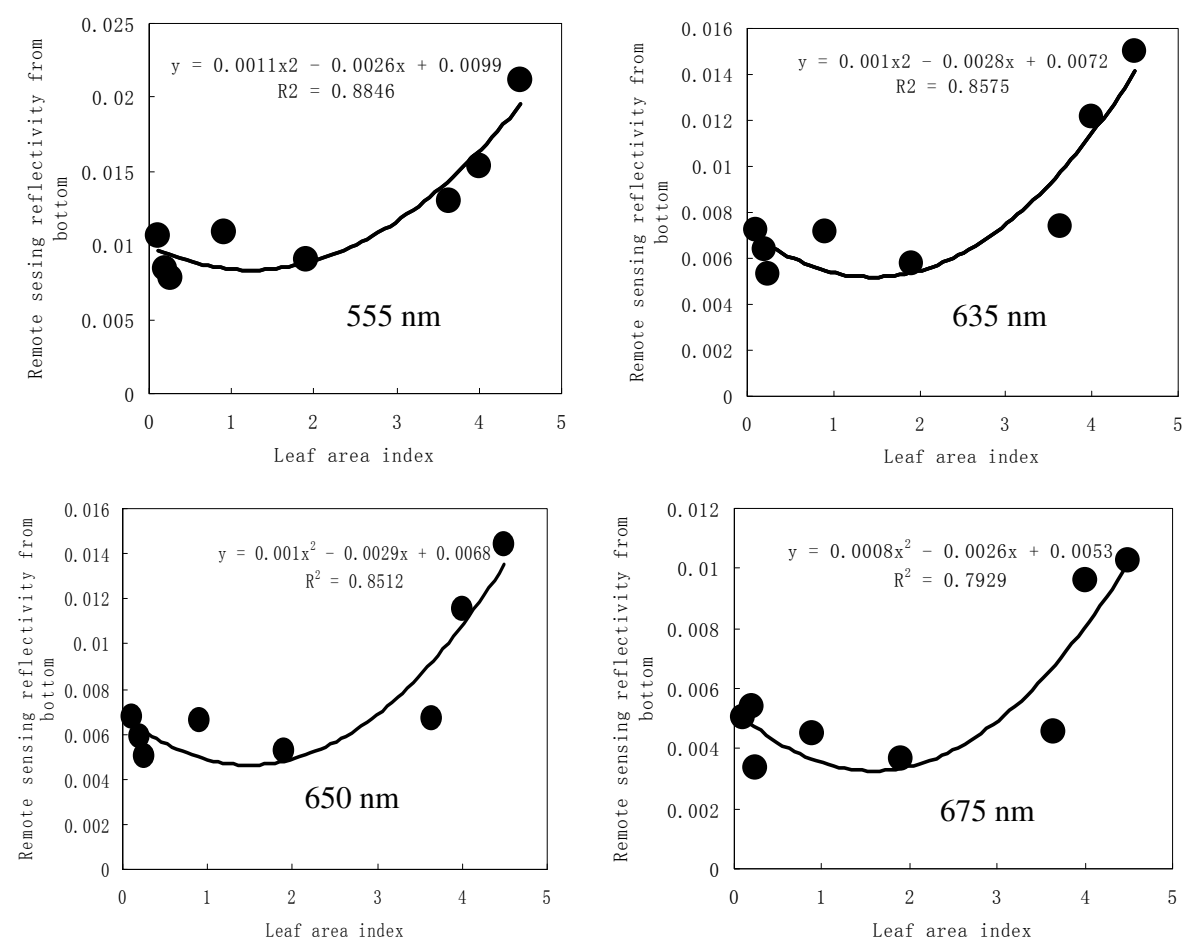

Fig. 6. Relationship between seagrass LAI and different hyperspectral band (Yang et al. 2011b) 
pigment, the results in the paper are also confident with the results of previous study. Compared with Quickbird bands (Band1 $(0.45-0.52 \mu \mathrm{m}), 2(0.52-0.59 \mu \mathrm{m}), 3(0.63-0.69 \mu \mathrm{m})$ and $4(0.77-0.89 \mu \mathrm{m}))$. Band 2 and band 3 of Quickbird can be well used for retrieving seagrass distribution.

\subsection{The peak location and LAI}

Red edge refers to the region of rapid change in reflectance of chlorophyll in the near infrared range. Vegetation absorbs most of the light in the visible part of the spectrum but is strongly reflective at wavelengths greater than $700 \mathrm{~nm}$. The change can be from $5 \%$ to $50 \%$ reflectance between $680 \mathrm{~nm}$ to $730 \mathrm{~nm}$. The phenomenon accounts for the brightness of foliage in infrared photography. It is used in remote sensing to monitor plant activity and could be useful to detect light-harvesting organisms on distant planets. Fig.7 also shows the typical reflectance characteristics of seagrass with an obvious spectral peak at red edge, and the peak at the wavelength of $695-710 \mathrm{~nm}$ range shifted to the red with increasing of leaf areas. Fig.7 indicates a strong relationship between the peak location and LAI with a coefficient of correlation of 0.7263 in the near infrared range.

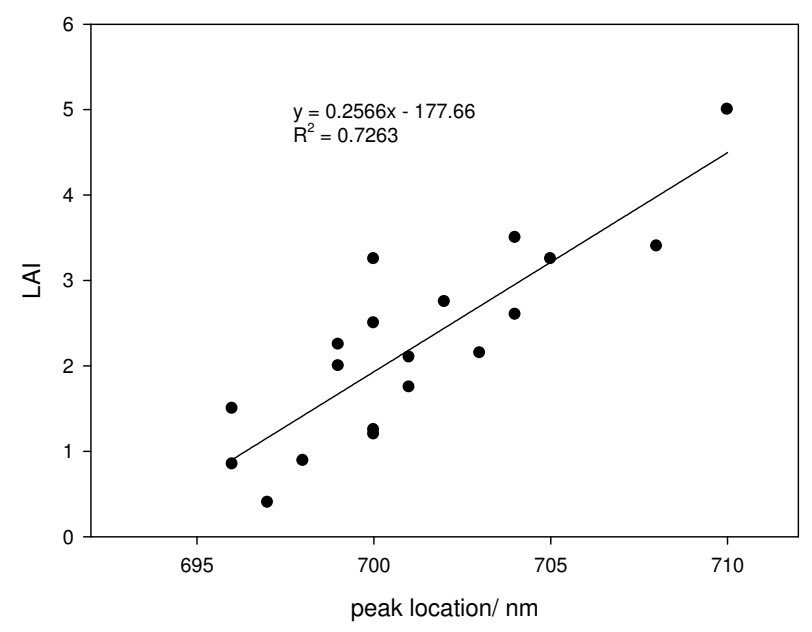

Fig. 7. Relationship between the peak location and LAI (Yang et al. 2010).

\subsection{Relationship between seagrass LAI, NDVI and Hyperspectral Bands}

The Normalized Difference Vegetation Index (NDVI) is a simple numerical indicator that can be used to analyze remote sensing measurements. In order to fully explore the useful information in hyperspectra, the red band reflectance of NDVI was replaced by the green and blue band reflectance. The equations are listed as follows:

$$
\begin{array}{cc}
\text { Red NDVI } & \text { RNDVI }=(\text { NIR-Red }) /(\mathrm{NIR}+\mathrm{Red}) \\
\text { Green NDVI } & \text { GNDVI=(NIR-Green) } /(\mathrm{NIR}+\mathrm{Green}) \\
\text { Blue NDVI } & \text { BNDVI }=(\mathrm{NIR}-\mathrm{Blue}) /(\mathrm{NIR}+\mathrm{Blue})
\end{array}
$$


where, NIR is near infrared reflectance. In the paper, VNDVI is taken as the general name of BNDVI, GNDVI and RNDVI. Hyperspectra, leaf area index and NDVI (Normalized Difference Vegetation Index) of seagrass were measured and calculated with equations $(5,6$, 7), and the relationship between them was obtained.

As Fig.8 indicates, the spectral reflectance of seagrass measured at different stations changed regularly with LAI. The bands with a good correspondence with LAI were 555, 635, 650 and $675 \mathrm{~nm}$, for absorption and reflectance of seagrass photosynthetic and accessory pigment. However, at the band around 400 and $720 \mathrm{~nm}$, a relatively poor relationship with LAI was found (Table 1). The peaks and troughs on the reflectance spectra were also affected by factors such as reflectance and transmission of single leaves, types of background, leaf angle, the geometry of sun and sensor angles, etc, and these effects can be reduced to great extent when hyperspectral measurement are taken in situ.

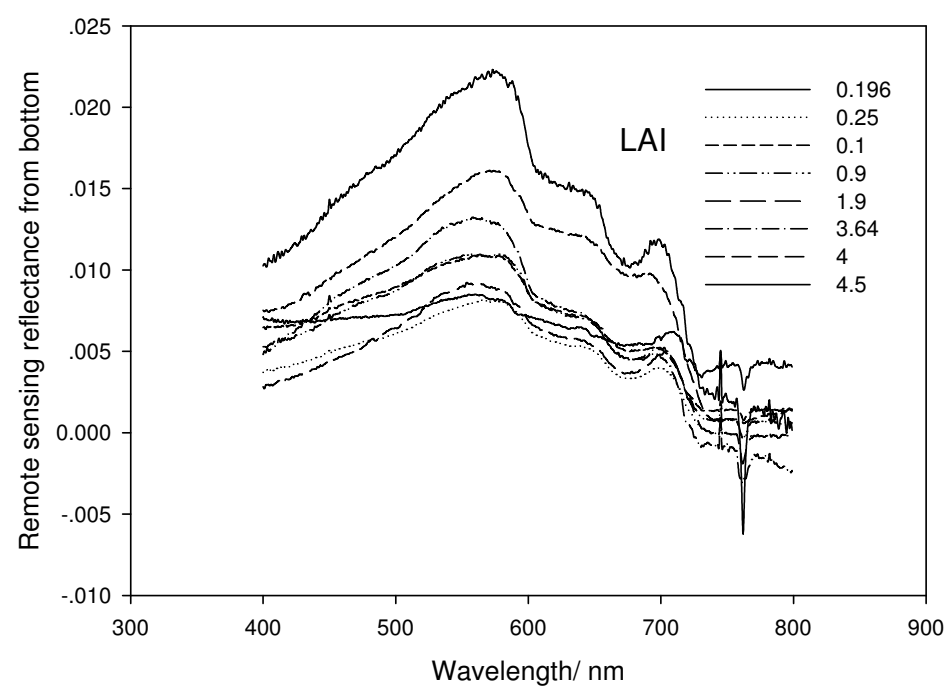

Fig. 8. Relationship between spectral bands and seagrass LAI (Yang et al. 2009).

\begin{tabular}{lll}
\hline $550 \mathrm{~nm}$ & $\mathrm{y}=0.0011 \mathrm{x}^{2}-0.0026 \mathrm{x}+0.0099$ & $\mathrm{R}^{2}=0.8846$ \\
$635 \mathrm{~nm}$ & $\mathrm{y}=0.001 \mathrm{x}^{2}-0.0028 \mathrm{x}+0.0072$ & $\mathrm{R}^{2}=0.8575$ \\
$650 \mathrm{~nm}$ & $\mathrm{y}=0.001 \mathrm{x}^{2}-0.0029 \mathrm{x}+0.0068$ & $\mathrm{R}^{2}=0.8512$ \\
$675 \mathrm{~nm}$ & $\mathrm{y}=0.0008 \mathrm{x}^{2}-0.0026 \mathrm{x}+0.0053$ & $\mathrm{R}^{2}=0.7929$ \\
$400 \mathrm{~nm}$ & $\mathrm{y}=0.0011 \mathrm{x}^{2}-0.0041 \mathrm{x}+0.0068$ & $\mathrm{R}^{2}=0.7728$ \\
$700 \mathrm{~nm}$ & $\mathrm{y}=0.0008 \mathrm{x}^{2}-0.0024 \mathrm{x}+0.0057$ & $\mathrm{R}^{2}=0.7604$ \\
\hline
\end{tabular}

Table 1. Relationship between LAI and different hyper spectral band. In Table 1, y is remote sensing reflectivity from bottom, $x$ is LAI. 
In order to monitor seagrass with satellite remote sensing, the relationship between Leaf Area Index (LAI) and the Normalized Difference Vegetation Index (NDVI) was correlated. Analysis indicated that a good relationship existed between NDVI and LAI. Relationships between every VNDVI (RNDVI, GNDVI and BNDVI) and LAI were studied. Fig.9 shows that the VNDVI increased with the increase of LAI. The correlation coefficient between GNDVI and LAI (0.7357) was better than the RNDVI (0.6705) and BNDVI (0.6729), which means that GNDVI is more sensitive than RNDVI and BNDVI when applied to seagrass remote sensing. However, when LAI is less than 1.5, the correlation coefficient between VNDVI and LAI is relatively low. A0s the band set in the visible and infrared of the satellite remote sensing data (CBERS, Landsat TM, and QuickBird) is blue $(0.45-0.52 \mu \mathrm{m})$, green $(0.52-$ $0.59 \mu \mathrm{m})$, red $(0.63-0.69 \mu \mathrm{m})$ and infra-red $(0.77-0.89 \mu \mathrm{m})$, NDVI was retrieved with blue, green and red also, which is compatible with the satellite data band set.

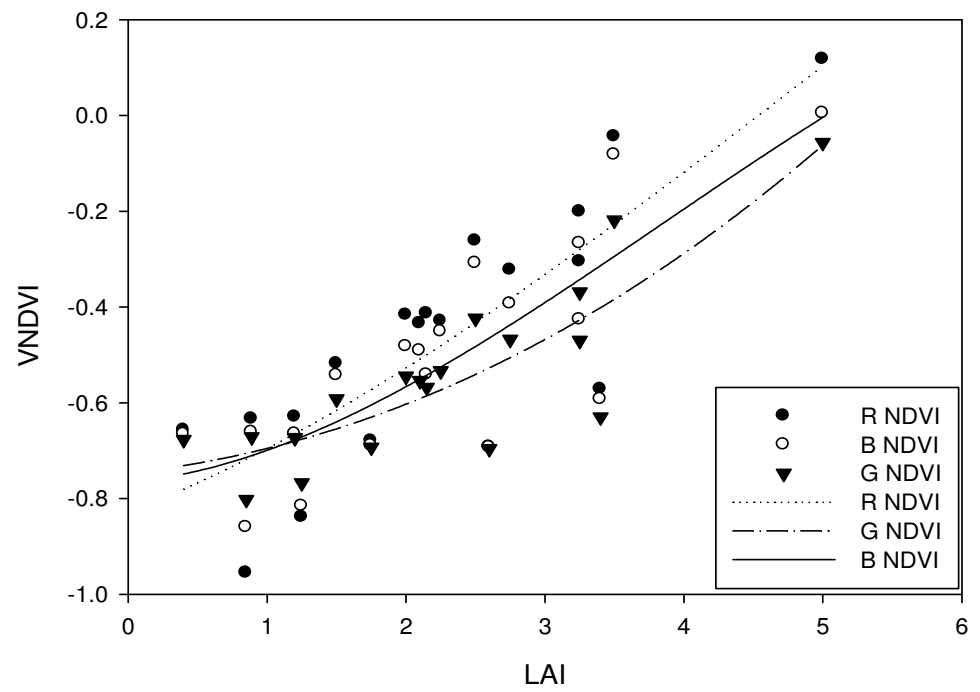

Fig. 9. Relationship between LAI and NDVI (Yang et al. 2009).

\subsection{Seagrass detection with satellite remote sensing}

QuickBird data was used for correcting seagrass density and detailed distribution retrieved with Landsat and CBERS data, for detailed seagrass distribution was very important for us to compare seagrass distribution changes (Yang and Yang 2009). With the water body correction, sun glint correction and computation of bands, seagrass distribution along the south coast of Xincun Bay was retrieved and showed in Fig 10 (Yang 2008). From the Quickbird image, substrate types, such as sand, seagrass can be detected clearly, and the profiles from bank to the center of Xincun Bay were sea pond, sand, seagrass and optically deep water. In shallow water near bank and relatively deeper water, no seagrass can be detected. The pattern of seagrass distribution can be detected clearly, and seagrass mainly distributed in the pattern of cluster, with tens meter distance away from the bank. 


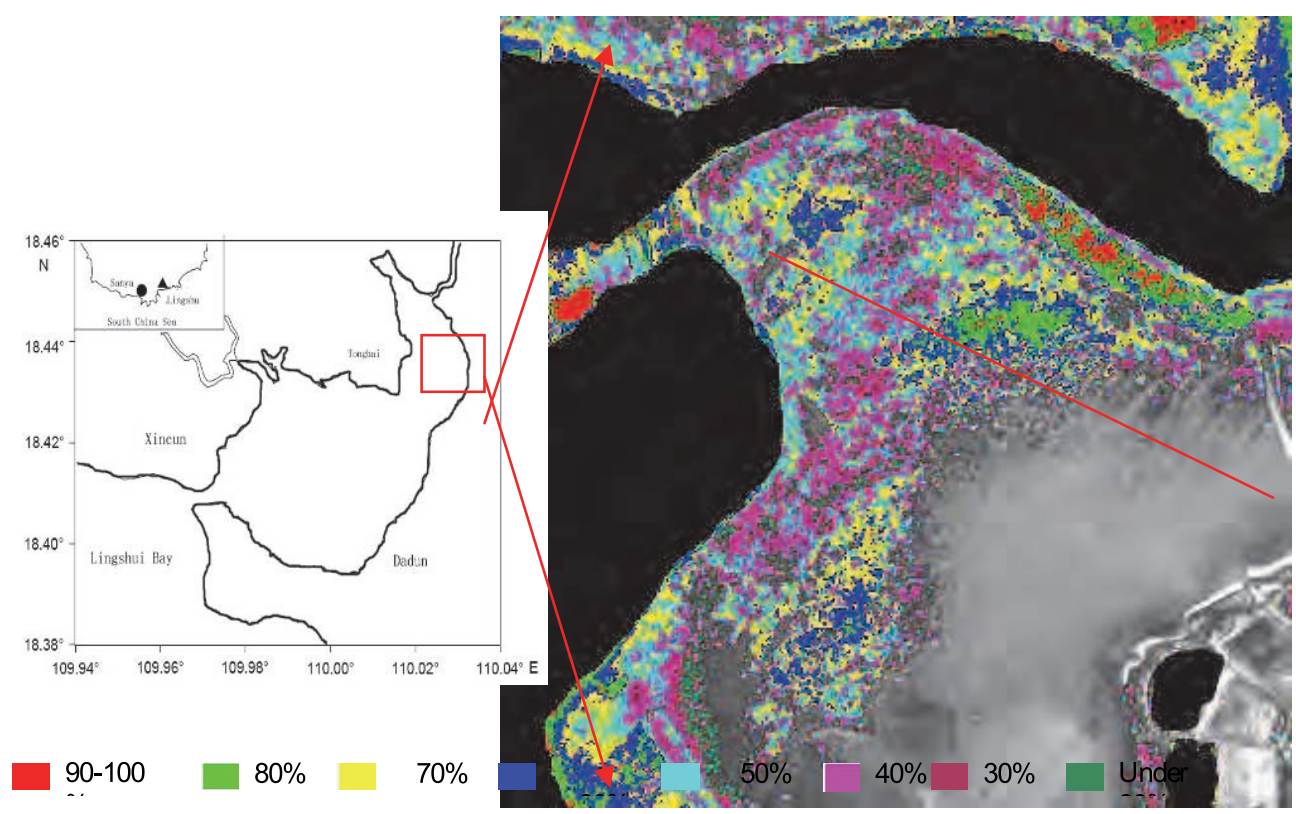

Fig. 10. Seagrass distribution in the northwest of Xincun Bay with Quickbirds (Yang et al. 2011b).

The pattern of seagrass distribution can also be clearly classified, and seagrass was mainly distributed in a stripe pattern, some tens of meters away from the coastline (YANG and HUANG 2011a). Seagrass density is regular in the main seagrass bed. From the outside to the center of the main seagrass bed, seagrass distribution coverage was under $20 \%, 20-40 \%$, $40-60 \%, 60-80 \%$ and greater than $80 \%$. Among them, the area of seagrass coverage greater than $80 \%$ accounted for more than $30 \%$ of the total seagrass bed (Fig. 11). Seagrass species in

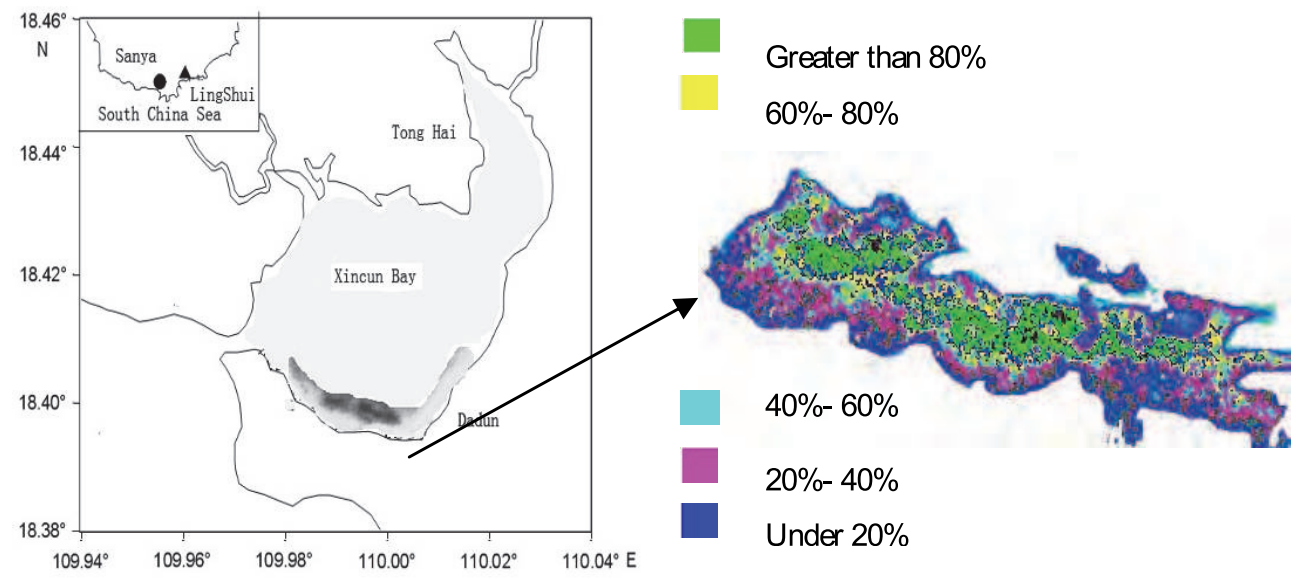

Fig. 11. Seagrass density retrieved with QuickBird (Yang et al. 2009). 
Xincun Bay are mainly Enhalus acoroides, Thalassia hemprichii, Cymodocea rotundata and Halodule uninervis; however, we could not differentiate one species from another with QuickBird data. Detection accuracy of seagrass with Quickbird data was mainly by comparing pixels of satellite remote sensing with in situ observations. In this paper, the accuracy was more than $80 \%$ for seagrass coverage greater than $20 \%$ when compared with the in situ observation results. Detailed information on seagrass distribution was very important for us to know the density of seagrass distribution and can be used as basis for comparing seagrass distribution changes. In order to further study seagrass distribution changes in Xincun Bay, Landsat TM and CBERS data was used (Yang et al. 2009). Compared with QuickBird, seagrass detected with Landsat TM and CBERS had fewer classes, which only showed the distribution range, for pattern and species cannot be clearly obtained. However, the distribution contour can be detected clearly, which was enough for comparison of seagrass distribution changes. Landsat data was usually used for detecting seagrass distribution for cost-effective and relatively higher revisit frequency, and visible band was regarded as the most useful. Lennon introduced the advantage of satellite remote sensing with Landsat TM data on detection of seagrass in 1989 and regarded red, blue and green as the most useful channel for detecting seagrass distribution (Lennon, 1989). Dahdouh-Guebas (1999) also used channel of blue, red and green of Landsat TM data to map the distribution of seagrass in Kenyan coast with good results.

The imperfect was that band spectrum coverage was relatively wider and the pixel sizes $(20-30 \mathrm{~m})$ are of a similar magnitude to the size of the habitat patches. So it was problematical when applied Landsat data on detecting seagrass in small area and distinguishing seagrass species. In 1970s, Yang et al (1979) investigated the seagrass distribution in the Chinese costal water, and distribution of seagrass in coastal water of Hainan province showed in the references. However, seagrass in the west coast of Hainan province disappeared in recent years. Some researchers regarded that it is mainly caused by aquaculture. Seagrass distributed in the east coast of Hainan province only confined within a few bays. Because different species of seagrass live in different environment, distribution of seagrass is confined by its growth habitat. Generally speaking, vertical distribution of seagrass from coastal to relative deep water around the coast of Hainan Province were Halophila, Cymodocea, Syringgodium, Ehaus, Thalassia, Ha-lophila. Substrates of sand, seagrass and coral were differentiated with different reflective characteristics. Based on the results, we can find that area of seagrass distribution in Sanya bay decreased, from distributed in the whole south coast in 1991 to less than 1 hectare in southwest coast of Sanya bay in 1999 (Fig 12).

Seagrass distribution in the south coast of Xincun Bay was mainly studied (Yang et al. 2009). In order to compare seagrass distribution in detail, we divided seagrass distribution regions as A, B and C (Fig. 12). Seagrass distribution in region A and region B was connected as one big seagrass bed in 1991, however, the two region seagrass separated gradually and they were only connected with a line of seagrass in 1999. Finally, complete separation was observed in 2001. Seagrass distribution in region C was relatively large with an elliptical shape in 1991; however, the shape of seagrass bed became thinner by 1999 and became a line in 2001. In 2006, seagrass at region C could be detected with satellite remote sensing. 

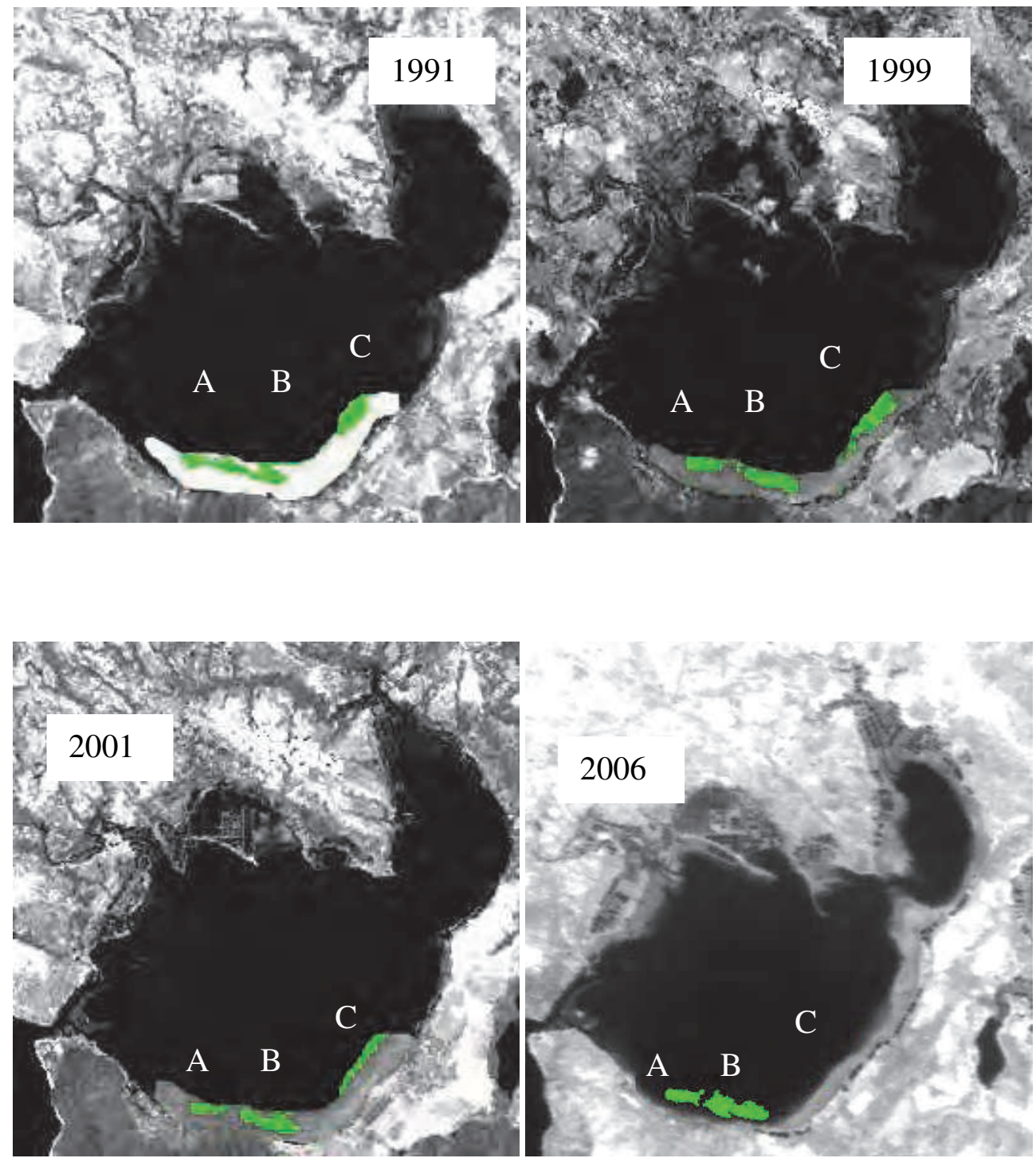

Fig. 12. Seagrass distribution change from 1991 to 2006 (Yang et al. 2009). 


\section{Impacts of environmental factors for seagrass distribution}

\subsection{Effluent diffusion in Sanya Bay}

As water with high concentration of nutrients in Sanya River flow into Sanya Bay, it diffused by current and wave. The effluent plume streaming out of the Sanya river into the Sanya Bay flows straight for only a short distance before it is washed westward by the longshore current (Yang 2008). Sanya Bay is an open bay, the flows-in water only stay in a short time. Landsat TM data of 1991 was used to detect the diffuse pattern in Sanya Bay. From the satellite images, the water plume of Sanya River mainly distributed along the south of Sanya Bay. The reason is when tidal water rushed into Sanya Bay it splits and flows back from the south of Sanya Bay. In Sanya Bay, Seagrass mainly distributed along the north coast of Lu Huitou peninsular, the plume of Sanya River affected seagrass distribution in great extent.

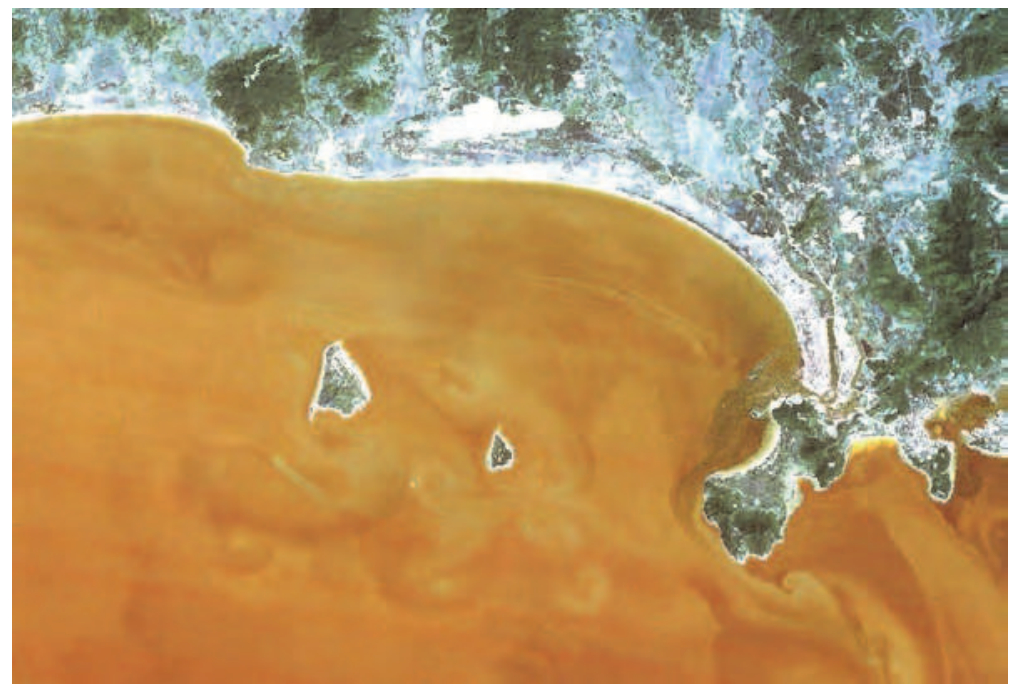

Fig. 13. The diffuse pattern of flows-in water in Sanya Bay (Yang 2008).

\subsection{Land use change}

Satellite Landsat data was used to retrieve land use change around Sanya bay. Sanya River and the island between the two rivers was chose as land use change indexes (Yang 2008). From the satellite images, area of eastern and western Sanya Rivers reduced in 1999 compared with that in 1991. However the area of island between the two rivers enlarged more than $30 \%$. The decreased river area, correspondently decreased the ecological wet land along the Sanya River, reduced the area for waste water cleaning. Seashore land use change was also retrieved with remote sensing data. From remote sensing data, the shape of costal line at the northeast of $\mathrm{Lu}$ Huitou peninsular changed greatly. In situ observation proved that buildings were constructed just along the coastal line. In situ observation also found that coast at the middle north of Lu Huitou peninsular was constructed as sea bath and sea diving area. 


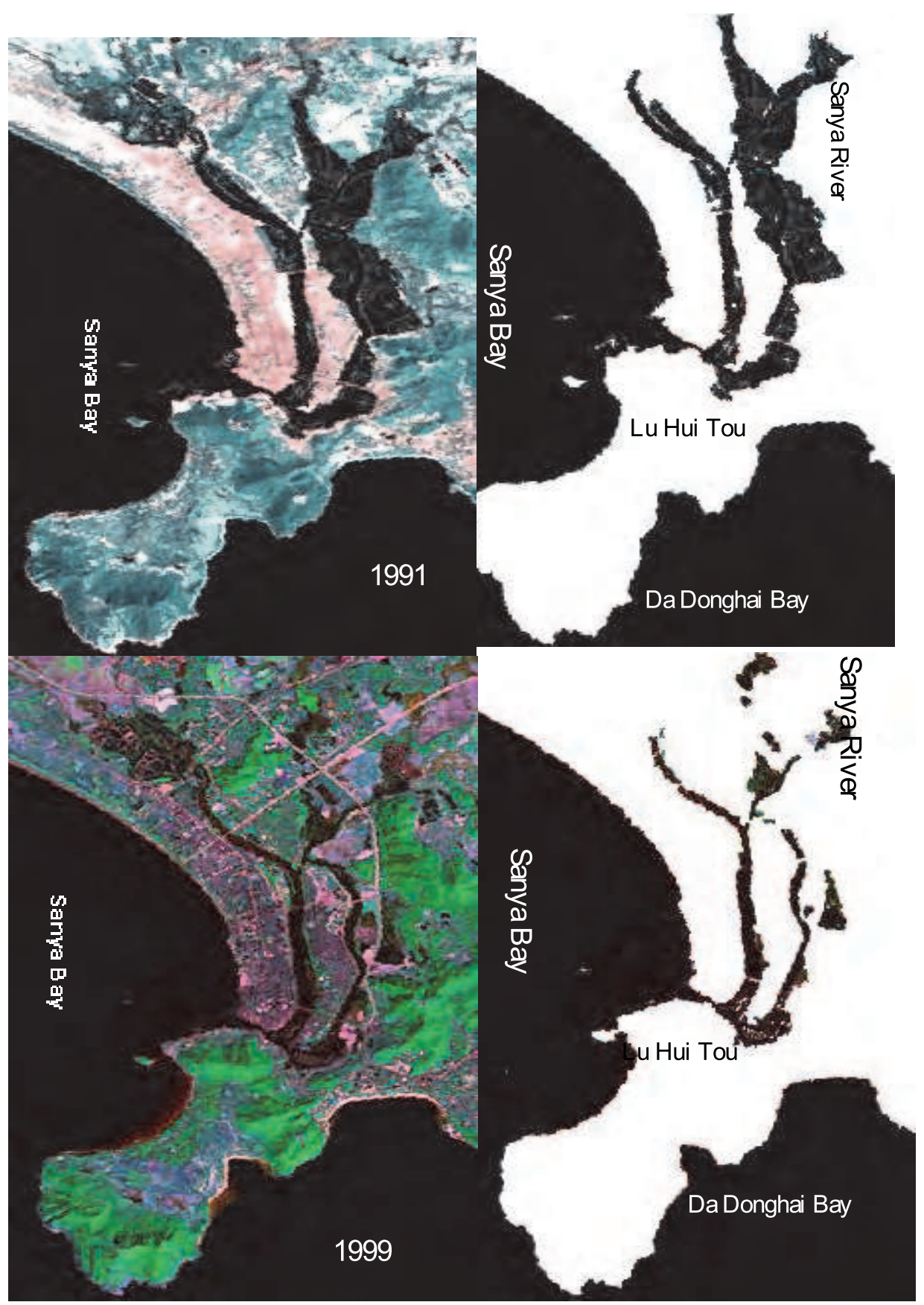

Fig. 14. Landsat TM data of Land use change around Sanya Bay in 1999 compared with that of in 1991 (Yang 2008). 


\subsection{Tendency of water chemical indexes by land use change in Sanya Bay}

Water quality of Sanya River and Sanya Bay, such as water transparency and water quality indexes, was provided by Sanya ecological field station and references. In situ water chemical data of inorganic nitrogen, phosphorus and chlorophyll a concentration was used for validation and correction of the results from satellite remote sensing data. Results showed that water quality of Sanya River degraded in 2002 compared with that in 1991 (Fig.15) ; water quality in Sanya bay near the Sanya River mouth was also degraded. However, water quality in other part of Sanya bay changed little. Perhaps Sanya bay is an open bay, where water exchange rate is relatively high.

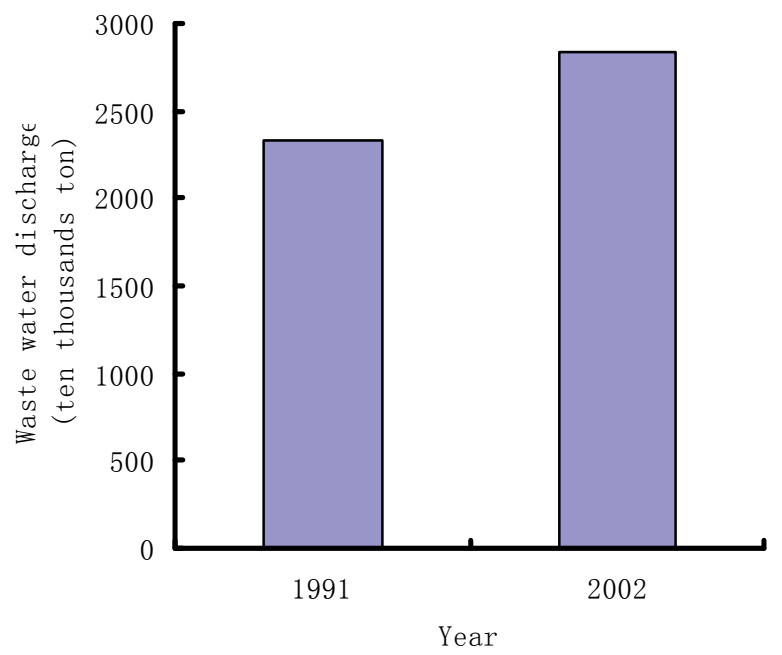

Fig. 15. Waste water discharge in Sanya Bay in 1991 and 2002 (Yang 2008).

\subsection{Relationship between land use change and seagrass distribution}

Seagrass distribution in Sanya area conversely correlated with land use change, the more area of land use change the less coverage of seagrass distribution. This mainly because distribution of seagrass was confined by the following factors: (1) Sediments, in the area close to the bank, were sand and frequently affected by hydrodynamics, on which seagrass cannot grow flourish. (2) Human activities, such as aquaculture, digging clam worm and ship sailing, also affected seagrass growth in shallow waters; (3)Transparency was also an important factor for seagrass growth. Clear water mainly distributed in the southwest of Sanya Bay, which provided the suitable condition for large area continuous seagrass distributed in the area.

\section{Discussions and conclusions}

As described in our investigation, much is known about the photophysiology of seagrass, while much is still required for us to effectively manage this important yet diminishing resource. New coastal ocean remote sensing techniques permit benthic habitats to be explored with higher resolution than ever before, however, the application of ocean color 
remote sensing to quantitative mapping of sparse seagrass species is still in its early development.

An optical model was proposed to simulate the radiation transfer in multi-layer, nonhomogenous, heterogeneous, natural media. This algorithm enables us to simulate radiation fields in a wide range of variations of optical characteristics of these layers and to analyze the mechanisms of the formation of the radiation characteristics inside and outside the layers, as well as to estimate any contribution of each region. Based on the algorithm, we appropriately removed the distorting influence of the water column on the remotely sensed signal to retrieve an estimate of the reflectance of seagrass. Implementation of the method was found to be effective for improving the accuracy of coastal habitat maps and essential for deriving empirical relationships between remotely sensed data and features of interest in the marine environment. Retrieved bottom reflectance was then used to study the optical characteristics of seagrass. Through spectrum analysis it was found that the wavelengths for the discrimination and mapping of seagrass meadows of Sanya Bay, South China Sea lay between $500-630 \mathrm{~nm}$ as well as $680-710 \mathrm{~nm}$. An appropriate hyper spectral band set for the remote sensing of seagrass should include narrow bands (maximum 5-10 nm bandwidth) centered around 555, 650, 675 and $700 \mathrm{~nm}$. If satellite images were used, the effect of atmosphere should be taken into account. Though the blue band is more easily affected by atmosphere, the accurate surface reflectance could be acquired with the development of the theory and models in atmosphere correction. The relationship between seagrass leaf area index (LAI) and hyperspectra is very important when satellite remote sensing data is applied for detecting seagrass distribution.

Seagrass distribution in Xincun Bay spanning 15 years (1991-2006) was retrieved with satellite remote sensing. From the seagrass detection results, the resolution of satellite remote sensing image is very important for seagrass detection, so QuickBird data was more suitable for seagrass detection than Landsat TM and CBERS, especially when the seagrass distribution area was relatively small. Results in the paper proved that five classes can be classified clearly with QuickBird; however, only seagrass distribution contours can be detected with Landsat TM and CBERS data.

Though the accuracy of seagrass detection with satellite remote sensing can be affected by many factors, seagrass in Xincun Bay can be detected clearly for the sediment there was sand. Compared with satellite remote sensing data in 1991, the seagrass distribution area was reduced gradually and large areas of seagrass had disappeared by 2006. Human activities and extreme natural disasters were the main reasons for seagrass reduction, especially land use changes in recent years. The effect of land use change on seagrass distribution can be concluded as following: seagrass distribution in Sanya area conversely correlated with land use change, the more area of land use change the less coverage of seagrass distribution. Mainly because of land use change changed the water quality and sediment type.

Except for hydrodynamic effect, distribution of seagrass was also affected by the following factors: (1) Sediments, in the area close to the bank, were sand and frequently affected by hydrodynamics, on which seagrass cannot grow flourish. (2) Human activities, such as aquaculture, digging clam worm and ship sailing, also affected seagrass growth in shallow waters; (3)Transparency was also an important factor for seagrass growth. Clear water 
distributed in the northeast of Xincun Bay, which provided the suitable condition for large area continuous seagrass distributed in the area.

Human activities, such as construction of shrimp ponds, aquaculture, fishing with standing net, clam digging, boat sailing, capturing prawns and fishes with blasting and trawling, affected seagrass growth in shallow waters. The area dedicated to shrimp ponds increased greatly in recent years, which had great negative effects on seagrass distribution.

\section{Acknowledgment}

The National Basic Research Program of China (973 Program) under grant No.2010CB951203; the National Natural Sciences Foundation of China under grant No. 41176161 and No. 40876092; the National Natural Sciences Foundation of Guangdong Province under grant No.8351030101000002.

\section{References}

Andrefouet, S., \& Guzman, H. M. (2005). Coral reef distribution, status and geomorphologybiodiversity relationship in Kuna Yala (San Blas) archipelago, Caribbean Panama. Coral Reefs, Vol.24, No.1, pp. 31-42, ISSN. 0722-4028.

Batish, S. (2002). Demonstration of the Impact of Land Use on the Benthic Habitats of the U. S.Virgin Islands with LandSat Satellite Imagery. Littoral 2002, The Changing Coast. EUROCOAST / EUCC, Porto - Portugal Ed. EUROCOAST - Portugal, ISBN 972-855809-0,103.

Becker, B. L., Lusch, D. P., \& Qi, J. G. (2005). Identifying optimal spectral bands from in situ measurements of Great Lakes coastal wetlands using second-derivative analysis. Remote Sensing of Environment, Vol.97, No.2, pp. 238-248, ISSN. 0034-4257.

Cannizzaro, J. P., \& Carder, K. L. (2006). Estimating chlorophyll a concentrations from remote-sensing reflectance in optically shallow waters. Remote Sensing of Environment, Vol.101, No.1, pp. 13-24, ISSN. 0034-4257.

Chami, M., Mckee, D., Leymarie, E., \& Khomenko, G. (2006). Influence of the angular shape of the volume-scattering function and multiple scattering on remote sensing reflectance. Applied Optics, Vol.45, No.36, pp. 9210-9220, ISSN. 1539-4522.

Conger, C. L., Hochberg, E. J., Fletcher, C. H., \& Atkinson, M. J. (2006). Decorrelating remote sensing color bands from bathymetry in optically shallow waters. Ieee Transactions on Geoscience and Remote Sensing, Vol.44, No.6, pp. 1655-1660, ISSN. 0196-2892.

Cummings, M. E., \& Zimmerman, R. C. (2003). Light harvesting and the package effect in the seagrasses Thalassia testudinum Banks ex Konig and Zostera marina L.: optical constraints on photoacclimation. Aquatic Botany, Vol.75, No.3, pp. 261-274, ISSN. 0304-3770.

Dahdouh-Guebas, F., Coppejans, E., \& Van Speybroeck, D. (1999). Remote sensing and zonation of seagrasses and algae along the Kenyan coast. Hydrobiologia, Vol.400, pp. 63-73, ISSN. 0018-8158.

Dekker, A. G., Malthus, T. J., Wijnen, M. M., \& Seyhan, E. (1992). Remote-Sensing as a Tool for Assessing Water-Quality in Loosdrecht Lakes. Hydrobiologia, Vol.233, No.1-3, pp. 137-159, ISSN. 0018-8158. 
Enriquez, S. (2005). Light absorption efficiency and the package effect in the leaves of the seagrass Thalassia testudinum. Marine Ecology Progress Series, Vol.289, pp. 141-150, ISSN. 0722-4028.

Froidefond, J. M., \& Ouillon, S. (2005). Introducing a mini-catamaran to perform reflectance measurements above and below the water surface. Optics Express, Vol.13, No.3, pp. 926-936, ISSN. 1094-4087.

Goodman, J. A., \& Ustin, S. L. (2007). Classification of benthic composition in a coral reef environment using spectral unmixing. Journal of Applied Remote Sensing, Vol.1, pp. -, ISSN. 1931-3195.

Gordon, H. R., \& Morel, A. Y. (1983). Remote assessment of ocean color for interpretation of satellite visible imagery: A review. ISBN 3-540-90923-0.

Hedley, J., Roelfsema, C., \& Phinn, S. R. (2009). Efficient radiative transfer model inversion for remote sensing applications. Remote Sensing of Environment, Vol.113, No.11, pp. 2527-2532, ISSN. 0034-4257.

Henyey, L. G., \& Greenstein, J. L. (1941). Diffuse radiation in the galaxy. The Astrophysical Journal, Vol.93, pp. 70-83, ISSN. 0004-637X.

Herbert, D. A., Perry, W. B., Cosby, B. J., \& Fourqurean, J. W. (2011). Projected Reorganization of Florida Bay Seagrass Communities in Response to the Increased Freshwater Inflow of Everglades Restoration. Estuaries and Coasts, Vol.34, No.5, pp. 973-992, ISSN. 1559-2723.

Holden, H., \& Ledrew, E. (2001). Effects of the water column on hyperspectral reflectance of submerged coral reef features. Bulletin of Marine Science, Vol.69, No.2, pp. 685-699, ISSN. 0007-4977.

Jacquemoud, S., Ustin, S. L., Verdebout, J., Schmuck, G., Andreoli, G., \& Hosgood, B. (1996). Estimating leaf biochemistry using the PROSPECT leaf optical properties model. Remote Sensing of Environment, Vol.56, No.3, pp. 194-202, ISSN. 0034-4257.

Lennon, P. J. (1989). Seagrass mapping using Landsat TM data. Avilable from http://www.gisdevelopment.net. (accessed August 15, 2006).

Liang, S. L. (2007). Recent developments in estimating land surface biogeophysical variables from optical remote sensing. Progress in Physical Geography, Vol.31, No.5, pp. 501516, ISSN. 0309-1333.

Maritorena, S., Morel, A., \& Gentili, B. (1994). Diffuse-Reflectance of Oceanic Shallow Waters - Influence of Water Depth and Bottom Albedo. Limnology and Oceanography, Vol.39, No.7, pp. 1689-1703, ISSN. 0024-3590.

Mobley, C. D. (1994). Light and Water: Radiative Transfer in Natural Waters. Academic, New York, ISBN-10: 0125027508 |.

Mobley, C. D. (1999). Estimation of the remote-sensing reflectance from above-surface measurements. Applied Optics, Vol.38, No.36, pp. 7442-7455, ISSN. 0003-6935.

Morel, A., \& Prieur, L. (1977). Analysis of Variations in Ocean Color. Limnology and Oceanography, Vol.22, No.4, pp. 709-722, ISSN. 0024-3590.

Morel, A., \& Gentili, B. (1991). Diffuse Reflectance of Oceanic Waters - Its Dependence on Sun Angle as Influenced by the Molecular-Scattering Contribution. Applied Optics, Vol.30, No.30, pp. 4427-4438, ISSN. 0003-6935.

Morel, A., \& Gentili, B. (1993). Diffuse-Reflectance of Oceanic Waters .2. Bidirectional Aspects. Applied Optics, Vol.32, No.33, pp. 6864-6879, ISSN. 0740-3224. 
Morel, A., \& Gentili, B. (1996). Diffuse reflectance of oceanic waters .3. Implication of bidirectionality for the remote-sensing problem. Applied Optics, Vol.35, No.24, pp. 4850-4862, ISSN. 0003-6935.

Nichols, T. D., \& Kyrala, G. A. (1992). Measurement of Irradiance Distribution at the Focus of a High-Irradiance Laser-Beam. Optical Engineering, Vol.31, No.12, pp. 2647-2656, ISSN. 0091-3286.

Orth, R. J., \& Moore, K. A. (1983). Chesapeake Bay - an Unprecedented Decline in Submerged Aquatic Vegetation. Science, Vol.222, No.4619, pp. 51-53, ISN. 00368075.

Pasqualini, V., Pergent-Martini, C., Pergent, G., Agreil, M., Skoufas, G., Sourbes, L., \& Tsirika, A. (2005). Use of SPOT 5 for mapping seagrasses: An application to Posidonia oceanica. Remote Sensing of Environment, Vol.94, No.1, pp. 39-45, ISSN. 0034-4257.

Peterson, B. J., \& Fourqurean, J. W. (2001). Large-scale patterns in seagrass (Thalassia testudinum) demographics in south Florida. Limnology and Oceanography, Vol.46, No.5, pp. 1077-1090, ISSN. 0024-3590.

Phinn, S. R., Dekker, A. G., Brando, V. E., \& Roelfsema, C. M. (2005). Mapping water quality and substrate cover in optically complex coastal and reef waters: an integrated approach. Marine Pollution Bulletin, Vol.51, No.1-4, pp. 459-469, ISSN. 0025-326X.

Phinn, S., Roelfsema, C., Dekker, A., Brando, V., \& Anstee, J. (2008). Mapping seagrass species, cover and biomass in shallow waters: An assessment of satellite multispectral and airborne hyper-spectral imaging systems in Moreton Bay (Australia). Remote Sensing of Environment, Vol.112, No.8, pp. 3413-3425, ISSN. 0034-4257.

Sathe, P. V., \& Sathyendranath, S. (1992). A Fortran-77 Program for Monte-Carlo Simulation of Upwelling Light from the Sea. Computers E Geosciences, Vol.18, No.5, pp. 487-507, ISSN. 0098-3004.

Yang, C. Y., Yang, D. T., Cao, W. X., Zhao, J., Wang, G. F., Sun, Z. H., Xu, Z. T., \& Kumar, M. S. R. (2010). Analysis of seagrass reflectivity by using a water column correction algorithm. International Journal of Remote Sensing, Vol.31, No.17-18, pp. 4595-4608, ISSN. 0143-1161.

Yang, D. T. (2008). Variation of seagrass distribution in Sanya Bay impacted by land use change. Geoinformatics 2008 and Joint Conference on GIS and Built Environment: Monitoring and Assessment of Natural Resources and Environments, Vol.7145, pp. 714529-714529-714528

Yang, D. T., \& Huang, D. J. (2011a). Impacts of Typhoons Tianying and Dawei on seagrass distribution in Xincun Bay, Hainan Province, China. Acta Oceanologica Sinica, Vol.30, No.1, pp. 32-39, ISSN. 0253-505X.

Yang, D. T., Y. Yang, C. Yang, J. Zhao \& Z. Sun. (2011b). Detection of seagrass in optical shallow water with Quickbird in Xincun Bay, Hainan province, China. IET Image Processing, Vol.5, No.5,pp.363-368. ISSN.1751-9667.

Yang, D. T., \& Yang, C. Y. (2009). Detection of Seagrass Distribution Changes from 1991 to 2006 in Xincun Bay, Hainan, with Satellite Remote Sensing. Sensors, Vol.9, No.2, pp. 830-844, ISSN. 1424-8220.

Yang, Z. D. (1979). The geographical distribution of seagrass. Bull. Limnol. Oceanogr, Vol.2, pp. 41-46, 


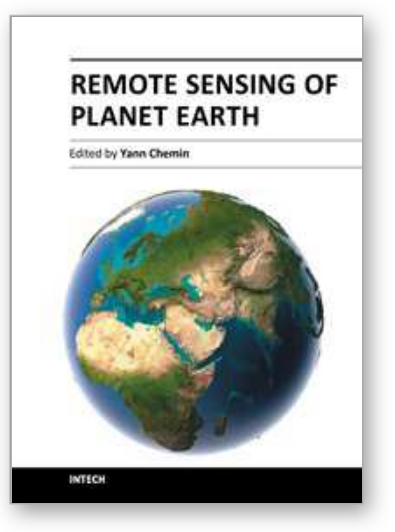

\author{
Remote Sensing of Planet Earth \\ Edited by Dr Yann Chemin
}

ISBN 978-953-307-919-6

Hard cover, 240 pages

Publisher InTech

Published online 27, January, 2012

Published in print edition January, 2012

Monitoring of water and land objects enters a revolutionary age with the rise of ubiquitous remote sensing and public access. Earth monitoring satellites permit detailed, descriptive, quantitative, holistic, standardized, global evaluation of the state of the Earth skin in a manner that our actual Earthen civilization has never been able to before. The water monitoring topics covered in this book include the remote sensing of open water bodies, wetlands and small lakes, snow depth and underwater seagrass, along with a variety of remote sensing techniques, platforms, and sensors. The Earth monitoring topics include geomorphology, land cover in arid climate, and disaster assessment after a tsunami. Finally, advanced topics of remote sensing covers atmosphere analysis with GNSS signals, earthquake visual monitoring, and fundamental analyses of laser reflectometry in the atmosphere medium.

\title{
How to reference
}

In order to correctly reference this scholarly work, feel free to copy and paste the following:

Yang Dingtian and Yang Chaoyu (2012). Seagrass Distribution in China with Satellite Remote Sensing, Remote Sensing of Planet Earth, Dr Yann Chemin (Ed.), ISBN: 978-953-307-919-6, InTech, Available from: http://www.intechopen.com/books/remote-sensing-of-planet-earth/seagrass-distribution-in-china-with-remotesensing

\section{INTECH}

open science | open minds

\author{
InTech Europe \\ University Campus STeP Ri \\ Slavka Krautzeka 83/A \\ 51000 Rijeka, Croatia \\ Phone: +385 (51) 770447 \\ Fax: +385 (51) 686166 \\ www.intechopen.com
}

\author{
InTech China \\ Unit 405, Office Block, Hotel Equatorial Shanghai \\ No.65, Yan An Road (West), Shanghai, 200040, China \\ 中国上海市延安西路65号上海国际贵都大饭店办公楼 405 单元 \\ Phone: +86-21-62489820 \\ Fax: +86-21-62489821
}


(C) 2012 The Author(s). Licensee IntechOpen. This is an open access article distributed under the terms of the Creative Commons Attribution 3.0 License, which permits unrestricted use, distribution, and reproduction in any medium, provided the original work is properly cited. 